\title{
Agent Based Simulation OF TRANSPORTATION LOGISTIC SYSTEMS
}

\author{
AdamKo, N.; KavickA, A. \& Klima, V.
}

Abstract: The contribution pays attention to simulation of large-scale transportation logistic systems based on a proprietary agent-based architecture (called ABAsim) supporting rapid and flexible prototyping of simulation models. ABAsim architecture utilizes the paradigm of autonomous agents, whereas it disposes of high degree of flexibility due to consistent hierarchical structure of relevant conceptual models, indirect addressing mechanism associated with inter-agent communication and exploitation of Petri nets for definitions of control procedures. The simulation model configuration can be built (using a specific CASE-tool) by replacing relevant submodels, individual agents or their internal components. There is also presented a generic simulation tool Villon (based on ABAsim architecture), its features and corresponding experience with its utilisation within simulations of complex transportation nodes.

Key words: Agent-Based Simulation, Petri nets, Simulation of Transportation Logistic Systems


Authors' data: Ing. PhD. Adamko, N[orbert]*; Doc. Ing. Ph.D. Kavicka, A[ntonin]**; Mgr. PhD. Doc. Klima, V[alent]*, * University of Žilina, Univerzitna 8215/1, 1026 Zilina, Slovak Republic, ** University of Pardubice, Studentská 95, 53210 Pardubice, Czech Republic, Norbert.Adamko@fri.uniza.sk, Antonin.Kavicka@upce.cz, Valent.Klima@fri.uniza.sk

This Publication has to be referred as: Adamko, N.; Kavicka, A. \& Klima, V. (2007). Agent Based Simulation of Transportation Logistic Systems, Chapter 36 in DAAAM International Scientific Book 2007, B. Katalinic (Ed.), Published by DAAAM International, ISBN 3-901509-60-7, ISSN 1726-9687, Vienna, Austria DOI: $10.2507 /$ daaam.scibook.2007.36 